\title{
A cytogenetic survey of men being investigated for subfertility
}

\author{
M. J. W. Faed*, J. Robertson*, M. A. Lamont*, W. MacIntosh†, \\ J. Grieveł, K. Baxby , G. B. James§ and A. M. Crowder \\ ${ }^{*}$ Cytogenetics Laboratory, $\dagger$ Department of Pathology, $\ddagger$ Department of Urology and \\ $\S$ Department of Obstetrics and Gynaecology, University of Dundee, Dundee DD2 1UB, U.K.
}

\begin{abstract}
Summary. A study of 336 men attending a subfertility clinic but otherwise unselected, and a further 12 men studied as a part of the investigation of the female partner, revealed 10 with major chromosome anomaly and 3 with unambiguous chromosomal variants. In addition to those with sex chromosome aneuploidy, an extra, small marker chromosome and D/D Robertsonian translocations, anomalies which have been reported in other studies, there were 7 men with rearrangements, including a paracentric inversion of chromosome 7 and an $X / 21$ reciprocal translocation. These would have been difficult or impossible to identify without good banded preparations, suggesting that such rearrangements may be more frequent in association with subfertility than was appreciated.
\end{abstract}

\section{Introduction}

Cytogenetic surveys of men attending subfertility clinics have been reported from various centres in recent years. Two of the larger studies are those by Kjessler (1972) of 1263 patients and by Chandley et al. (1975) of 1599 patients. Koulischer \& Schoysman (1974) reported observations on 202 patients and reviewed the findings of earlier reports.

From these sources it is becoming evident that certain karyotypes, known to occur in the general population, appear with increased frequency in subfertile men. The present survey, using a chromosome banding technique, was undertaken to clarify further the role of chromosomal anomaly in male infertility.

\section{Materials and Methods}

All men attending a subfertility clinic over the course of 4 years have been included in the survey. The total in this category was 336. Twelve others, who did not attend the clinic, had blood sent directly for cytogenetic analysis as part of the investigation of the female partner and these were also included.

The age range of the patients was $20-52$ years with a mean age of 29 years. The reasons for referral varied: 275 men complained of primary infertility with no known conceptions in the female partner, although 22 of the latter subsequently became pregnant. Secondary infertility, following the birth of one or more live children occurred in 27 couples. In 25 men from the clinic, and in 8 men referred directly, there was a history of spontaneous abortion in the spouse. Eight men were referred to the clinic for other causes, 4 for fertility assessment following known gonadal pathology and 4 because of impotence associated with medical disease. The reason for attending the clinic could not be ascertained for 5 men. 
There was no selection of the men; the survey covers men complaining of a wide range of subfertility, from temporary impairment of fertility to complete sterility. At their first visit to the clinic all patients had a blood sample taken for cytogenetic analysis. A minimum of 2 cells was examined from orcein-stained chromosome preparations and a further 2 cells were karyotyped after trypsin/Giemsa banding (Seabright, 1971).

Seminal analysis was carried out for most of the men attending the male subfertility clinic (Table 1) but was not undertaken for patients referred directly for cytogenetic studies. Sperm concentration was used as a guide to spermatogenic activity. When this was less than $30 \times$ $10^{6} / \mathrm{ml}$ in the first seminal sample two further specimens were examined and an average of the three sperm counts was recorded.

Table 1. Distribution of sperm counts in 303 men attending a subfertility clinic

\begin{tabular}{lccc}
\hline & $\begin{array}{c}\text { Sperm counts } \\
\left(\times 10^{6} / \mathrm{ml}\right)\end{array}$ & No. & $\%$ \\
\hline Normal & $>30$ & 154 & $50 \cdot 8$ \\
Moderate oligospermia & $5-30$ & 82 & $27 \cdot 1$ \\
Severe oligospermia & $<5$ & 33 & $10 \cdot 9$ \\
Azoospermia & 0 & 34 & $11 \cdot 2$ \\
\hline Total & & 303 & 100 \\
\hline
\end{tabular}

\section{Results}

\section{Chromosome analysis}

Chromosome spreads suitable for analysis on orcein-stained preparations were obtained from all but 2 of the 348 blood samples received. Satisfactory trypsin/Giemsa preparations were obtained from 285 samples. There were 10 patients who were found to have a previously undiagnosed, major chromosome abnormality (Table 2). Two of these had sex chromosome aneuploidy, one $47, \mathrm{XXY}$ and one $47, \mathrm{XYY}$; one had a very small metacentric supernumerary chromosome of uncertain origin bearing satellites on one pair of arms (Pl. 1, Fig. 1); two had Robertsonian D/D translocations, both $45, \mathrm{XY}, \mathrm{t}(13 \mathrm{q} 14 \mathrm{q})$; three had reciprocal translocations involving autosomes and there was one reciprocal translocation involving an $\mathrm{X}$ and 21 ( $\mathrm{Pl}$. 2, Fig. 2) and one had a paracentric inversion of chromosome 7 (Pl. 2, Fig. 3).

Table 2. Karyotypes and seminal analyses of 13 subfertile men found to have chromosomal abnormalities out of a total of 348 analysed

\begin{tabular}{llcc}
\hline Patient & Karyotype & $\begin{array}{c}\text { Sperm count } \\
\left(\times 10^{6} / \mathrm{ml}\right)\end{array}$ & $\begin{array}{c}\text { Mean \% of } \\
\text { abnormal forms }\end{array}$ \\
\hline E.M. & $47, \mathrm{XXY}$ & 0 & - \\
J.K. & $47, \mathrm{XYY}$ & $2 \cdot 8$ & 20 \\
D.W. & $47, \mathrm{XY},+\mathrm{mar}$ & 23 & 36 \\
D.H. & $45, \mathrm{XY}, \mathrm{t}(13 \mathrm{q} 14 \mathrm{q})$ & 8 & 39 \\
W.C. & $45, \mathrm{XY}, \mathrm{t}(13 \mathrm{q} 14 \mathrm{q})$ & 20 & 16 \\
D.A. & $46, \mathrm{XY}, \mathrm{t}(10 ; 22)(\mathrm{q} 11 ; \mathrm{q} 11)$ & Not assessed & - \\
G.G. & $46, \mathrm{XY}, \mathrm{t}(2 ; 10)(\mathrm{q} 33 ; \mathrm{q} 24)$ & 20 & 34 \\
L.C. & $46, \mathrm{XY}, \mathrm{t}(\mathrm{8} ; 9)(\mathrm{q} 24 ; \mathrm{q} 22)$ & Not assessed & - \\
F.S. & $46, \mathrm{Y}, \mathrm{t}(\mathrm{X} ; 21)(\mathrm{q} 23 ; \mathrm{q} 11)$ & 0 & - \\
R.M. & $46, \mathrm{XY}, \operatorname{inv}(7)(\mathrm{q} 22 ; \mathrm{q} 34)$ & 43 & 18 \\
M.G. & $46, \mathrm{XY}, \operatorname{inv}(9)(\mathrm{p} 11 ; \mathrm{q} 13)$ & 25 & 26 \\
B.P. & $46, \mathrm{XY}, \operatorname{inv}(9)(\mathrm{p} 11 ; \mathrm{q} 12)$ & 6 & 17 \\
A.C. & $46, \mathrm{XY}, 22 \mathrm{p}+$ & 0 & - \\
\hline
\end{tabular}




\section{PLATE 1}
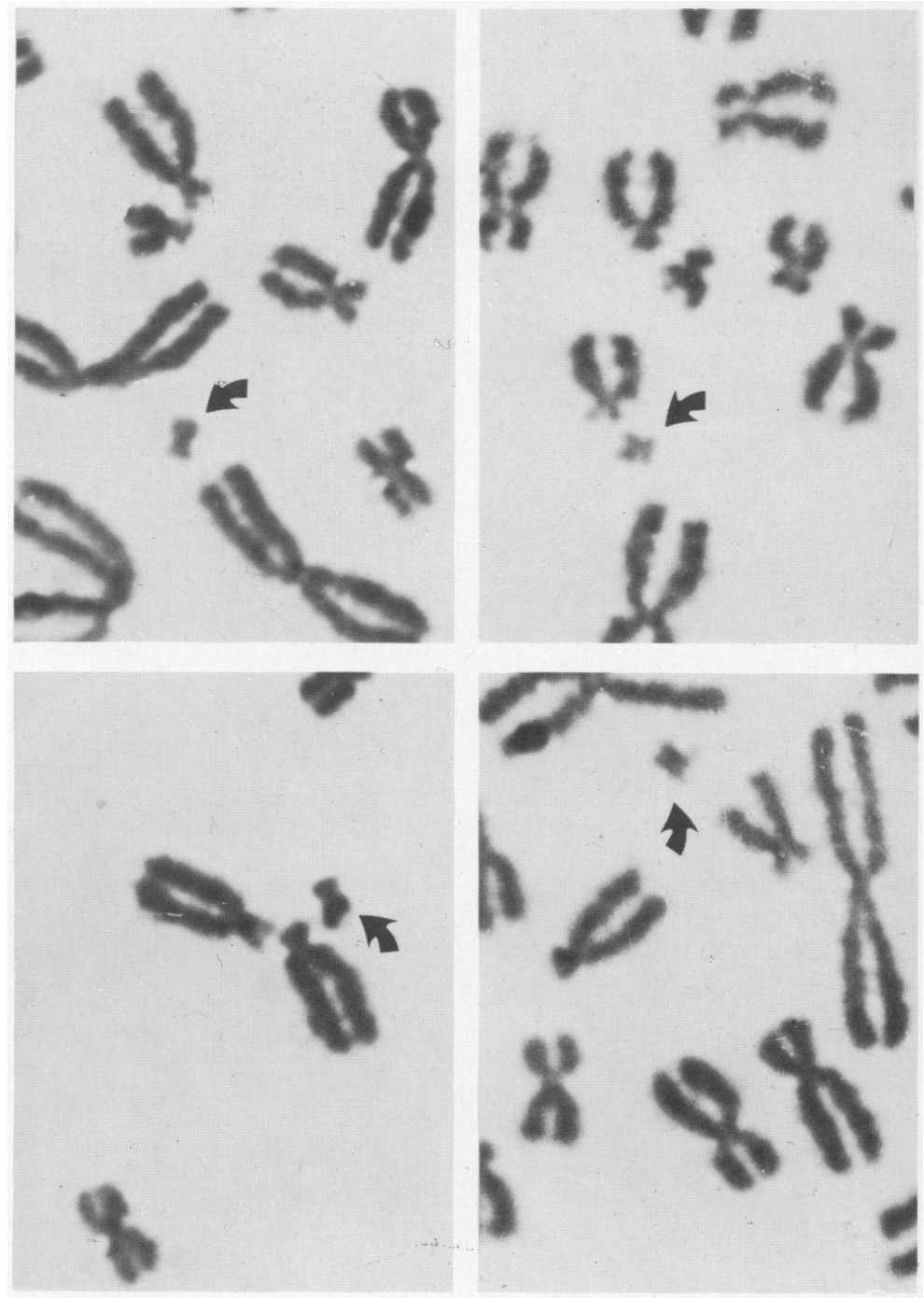

(1)

Fig. 1. Supernumerary marker chromosome from four cells of Patient D.W. Orcein stain.

(Facing p. 210) 
PLATE 2



1

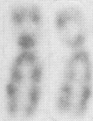

6

Rif 66

13

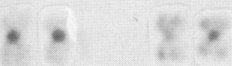

19

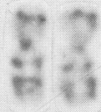

7

14

20

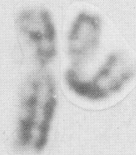

2

15

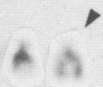

21

(2)
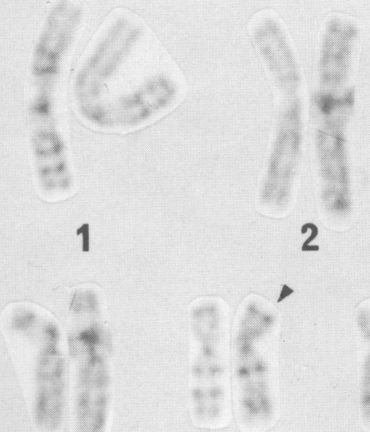

6

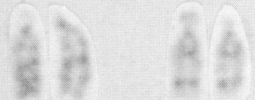

13

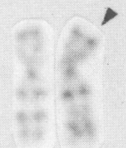

14

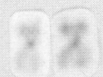

19

20

21

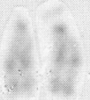

15

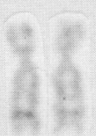

8

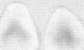

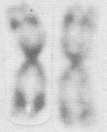

3

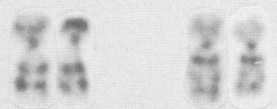

9

10

S. $\quad 4:$

16

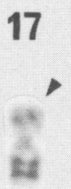

22

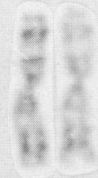

3

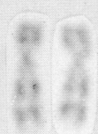

9

10
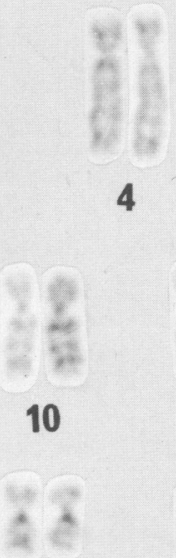

$\mathbf{x}$

4

5

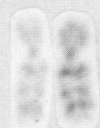

48
$y$

11

12

16

17

18

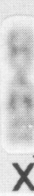

5

$\geq \frac{1}{4}$

12

21

18

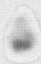

$Y$

(3) 
Several patients showed heteromorphism of a chromosome in the D and G groups or of chromosomes 9,16 and $\mathrm{Y}$. In view, however, of the uncertainty in defining the limits of variation found in these chromosomes only 3 of these patients, considered to have striking and completely unambiguous variant chromosomes, are considered further. Two of these had inversions of chromosome 9 and one had very large satellites on chromosome 22 which were highly fluorescent after atebrin staining.

\section{Seminal analysis}

Seminal specimens were obtained from 303 of the 336 men who attended the male subfertility clinic. The distribution of these, classified by sperm count, is shown in Table 1 . Almost half $(49.2 \%)$ of the men were classed as subfertile and of these $55 \%$ had mild to moderate oligospermia, $22 \%$ had severe oligospermia and $23 \%$ were azoospermic.

As shown in Table 2, azoospermia was present in the patient with Klinefelter's syndrome $(47, \mathrm{XXY})$, the patient with the large fluorescent satellites on chromosome 22 who also suffered from cystic fibrosis, and the patient with the $\mathrm{X} / 21$ reciprocal translocation. The carrier of the paracentric inversion of chromosome 7 was found to have an extremely variable sperm density but the mean count fell in the normal range. The patient with a 47,XYY karyotype had severe oligospermia, but all the other patients with chromosome abnormality and for whom sperm counts are available were in the mild to moderate range.

\section{Family studies}

Patients with subfertility are unenthusiastic about family investigation. We were able to examine only a limited number of relatives of our patients with chromosomal abnormality. The father of the patient (J.K.) with an extra Y chromosome had normal chromosomes. Among the patients with rearrangements it has been possible to examine blood from the near relatives of three. In the family of D.A. the translocation was also found in the father and sister of the propositus. The sister was fertile and gave no history of spontaneous abortion. The child of L.C., in addition to having Down's syndrome, carried his father's translocation; another child and a sister of the propositus, the only other family members tested, had normal chromosomes. The father of R.M. was a carrier of the paracentric inversion 7.

In view of the lack of full family investigations we collected the available data on the number of first degree relatives of those patients with a potentially heritable chromosomal anomaly so that should there be an inherited tendency to infertility this might be apparent in the sibship sizes (Table 3). Although the sibships of the patients are smaller than those of their parents there is no apparent tendency for the number of children to be noticeably depressed in one or other parental sibship.

\section{Case histories}

Patient E.M. had been married for 6 years before attending the clinic at the age of 29 years. He was the first child born after 7 years of marriage. At the time of this birth his mother was 27 ,

\section{PLATE 2}

Fig. 2. Trypsin-Giemsa banded karyotype of cell from Patient F.S. showing $X / 21$ reciprocal translocation (arrowed).

Fig. 3. Trypsin-Giemsa banded karyotype of cell from Patient R.M. showing paracentric inversion of chromosome 7 (arrowed). 
Table 3. Sibship sizes of patients with potentially heritable chromosome abnormality and of their first degree relatives

\begin{tabular}{llcccc}
\hline & & \multicolumn{4}{c}{ No. in sibship } \\
\cline { 3 - 6 } Patient & Karyotype & Patient & Offspring & Paternal & Maternal \\
\hline D.W. & $47, \mathrm{XY},+$ mar & 5 & 1 & 3 & 1 \\
D.H. & $45, \mathrm{XY}, \mathrm{t}(13 \mathrm{q} 14 \mathrm{q})$ & 1 & 0 & 7 & 5 \\
W.C. & $45, \mathrm{XY}, \mathrm{t}(13 \mathrm{q} 14 \mathrm{q})$ & 2 & 1 & 4 & 3 \\
D.A. & $46, \mathrm{XY}, \mathrm{t}(10 ; 22)$ & 2 & 2 & 4 & 3 \\
G.G. & $46, \mathrm{XY}, \mathrm{t}(2 ; 10)$ & 3 & 0 & 7 & 7 \\
L.C. & $46, \mathrm{XY}, \mathrm{t}(8 ; 9)$ & 2 & 2 & 3 & 6 \\
F.S. & $46, \mathrm{Y}, \mathrm{t}(\mathrm{X} ; 2 \mathrm{1})$ & 4 & 0 & 2 & 8 \\
R.M. & $46, \mathrm{XY}$, inv7 & 2 & 0 & 1 & 2 \\
\hline & & 2.6 & 0.75 & 3.9 & 4.4 \\
\hline
\end{tabular}

his father 34 . The only sib, a sister, was born 4 years later. No clinical abnormalities were noted apart from small testes which were both less than $1 \mathrm{~cm}$ diameter. He was azoospermic. A buccal smear was chromatin positive. All cultured lymphocytes examined had a 47, XXY karyotype.

Patient J.K. has been fully reported elsewhere (Faed, Robertson, MacIntosh \& Grieve, 1976). A clerk, he presented at the age of 28 years after 4 years of marriage. His height was 182 $\mathrm{cm}$. He had severe oligospermia, with $20 \%$ abnormal forms. Testicular biopsy revealed an incomplete spermatogenic arrest. Two $\mathrm{Y}$ bodies were present in cells from the buccal mucosa. Examination of lymphocytes showed a karyotype of 47,XYY.

Patient D.W. aged 29, was childless after 5 years of marriage but has fathered a son since attending the clinic. Two of his sibs, a sister and a brother, both had a gap of 7 years between marriage and the birth of their first and only child. His average sperm count was $23 \times 10^{6} / \mathrm{ml}$ with $36 \%$ abnormal forms. Chromosome studies revealed a small additional metacentric marker chromosome in all cells (Pl. 1, Fig. 1). The chromosome is small and its origin could not be identified. The longer arm shows satellite association in $84 \%$ of cells. Cord blood from the child was cultured but only cells with a 46,XY karyotype were found.

Patient D.H. presenting at the age of 32 years had been married for 8 years. He had no sibs. He was born after his parents had been married 3 years. There was no known history of maternal abortions. His father came from a sibship of 7 , all of whom were fertile; his mother

belonged to a sibship of 5 , all of whom were married but one brother had no children; 2 sisters and another brother had one child each. He had had a left variocoele treated 4 years previously. Seminal analysis showed an average sperm count of $8 \times 10^{6} / \mathrm{ml}$ with $39 \%$ abnormal forms. His karyotype was $45, \mathrm{XY}, \mathrm{t}(13 \mathrm{q} 14 \mathrm{q})$.

Patient W.C. attended the clinic after 2 years of involuntary sterility. He was a twin with no other siblings; the twin brother is not married. His mother belongs to a sibship of 3 , his father to a sibship of 4. His sperm count showed moderate oligospermia of $20 \times 10^{6} / \mathrm{ml}$ with $16 \%$ abnormal forms. A testicular biopsy showed tubules with normal spermatogenesis amongst others showing sloughing and disorganization. At 2 weeks after biopsy treatment with bromocriptin was started; a successful pregnancy ensued. The patient's karyotype was 45,XY, $\mathrm{t}(13 \mathrm{q} 14 \mathrm{q})$. No cells suitable for analysis were obtained from cord blood of the child.

Patient D.A. had fathered 2 girls but was referred because of repeated abortions in his wife. Five abortions, all over 14 weeks gestation had occurred, the most recent at 24 weeks (from the start of the last menstrual period). He is one of 2 sibs. His mother had no recognized abortions. His sister is married with one normal child. His karyotype is $46, \mathrm{XY}, \mathrm{t}(10 ; 22)(\mathrm{q} 11 ; \mathrm{q} 11)$; his sister and father also carry the translocation.

Patient G.G., aged 36 years, had a history of 15 years infertility throughout 2 marriages before presenting at the clinic. His mother was 43 at the time of his birth; two siblings, girls, 
were born 14 and 11 years previously. There is no history of maternal abortion. Both his sisters are fertile, one with 6 children and the other with 2 . His average sperm count was $20 \times 10^{6} / \mathrm{ml}$; the percentage of abnormal forms varied from 18 to $42 \%$. Testicular biopsy revealed maturation arrest at secondary spermatocyte level and meiotic studies (to be reported in detail elsewhere) showed a ring quadrivalent in all cells at diakinesis. His karyotype is $46, \mathrm{XY}, \mathrm{t}(2 ; 10)(\mathrm{q} 33 ; \mathrm{q} 24)$.

Patient L.C. was referred because of multiple abortions in his wife who had three abortions over 3 years, at 14, 8 and 10 weeks gestation, followed at 2-year intervals by a phenotypically normal son, another abortion of 10 weeks gestation and a son with Down's syndrome. The patient is the older of 2 sibs born 4 years apart. There is no known maternal history of abortion. His mother is one of 7 sibs, his father one of 3 males, one of whom is married with no family. The patient's karyotype was found to be $46, \mathrm{XY}, \mathrm{t}(8: 9)(\mathrm{q} 24 ; \mathrm{q} 22)$. His wife, sister and older son all have normal karyotypes. The younger son is $47, \mathrm{XY}, \mathrm{t}(8 ; 9)(\mathrm{q} 24 ; \mathrm{q} 22),+21$.

Patient F.S., aged 30, had been married for 6 years before attending the clinic. His wife had one child by a previous marriage. He is one of 4 sibs. He had a total parathyroidectomy following a hyper-parathyroid crisis 2 years previously but is now fit and stabilized with replacement therapy. He was found to be azoospermic. His karotype is $46, \mathrm{Y}, \mathrm{t}(\mathrm{X} ; 21)(\mathrm{q} 23 ; \mathrm{q} 11)$ (P1. 2, Fig. 2). No chromosome studies on the family of this patient have yet been possible.

Patient R.M., aged 33, attended the clinic after 7 years of marriage. He has one sibling, a girl born to his parents after 1 year of marriage; he was born 3 years later. His sister has been married for 5 years with no children. His wife had a myomectomy 1 year previously but investigation since had shown no abnormality in uterus, tubes or ovaries. Successive sperm counts, at intervals of 3 months, were $6 \times 10^{6} / \mathrm{ml}, 36 \times 10^{6} / \mathrm{ml}$ and $88 \times 10^{6} / \mathrm{ml}$. This patient was found to have a paracentric inversion of chromosome 7; 46,XY,inv(7)(q22;q34) (Pl. 2, Fig. 3). His father was also a carrier of the inversion.

Patient M.G. aged 29 years, had been married for 2 years. His wife had had 4 children by a previous marriage. He had 3 sibs all of whom were fertile. His sperm count was $25 \times 10^{6} / \mathrm{ml}$ with $26 \%$ of abnormal forms. His karyotype was $46, \mathrm{XY}$,inv(9)(p11;q13).

Patient B.P. attended at age 28 following 4 years of infertility although his wife is now pregnant. He had 2 brothers and 1 sister all of whom were fertile. His testes were small (1-1.5 $\mathrm{cm}$ diameter) and he had a history of prostatitis. Seminal analysis revealed an average sperm count of $6 \times 10^{6} / \mathrm{ml}$ with abnormal forms varying from 6 to $28 \%$. His karyotype is 46,XY,inv $(9)(\mathrm{p} 11 ; \mathrm{q} 12)$.

Patient A.C., aged 22 years, the youngest of 3 siblings, was unmarried but worried about his fertility. Both the siblings are fertile. His father belonged to a sibship of 6 and his mother to a sibship of 4. His karyotype was normal except for large, highly fluorescent satellites present on chromosome 22 . His mother has the same chromosome anomaly. He was known to have cystic fibrosis and was azoospermic.

\section{Discussion}

In 348 subfertile males we have found $3 \cdot 7 \%$ with a chromosomal abnormality. These results are compared in Table 4 with those from the survey of 1599 men karyotyped by Chandley et al. (1975) and the survey of 1263 men by Kjessler (1972). The route of referral of our patients was essentially similar to that in the first of these but in Kjessler's study a proportion of patients were referred after initial investigation at other regional centres and this is likely to introduce a bias in favour of more severe cases.

Both the Edinburgh study and ours show a considerably lower incidence of $47, \mathrm{XXY}$ individuals than that of Kjessler's, a difference probably due to selection of severe cases in that study. The incidence of Klinefelter's syndrome in our study is particularly low and although this 
Table 4. Incidence per thousand of individuals with chromosomal abnormality among subfertile patients compared with combined figures for newborn surveys

\begin{tabular}{|c|c|c|c|c|}
\hline \multirow[b]{2}{*}{ Karyotype } & \multicolumn{3}{|c|}{ Subfertile surveys } & \multirow{2}{*}{$\begin{array}{c}\text { Newborn surveys } \\
\text { quoted by } \\
\text { Neilsen \& Sillesen (1975) }\end{array}$} \\
\hline & $\begin{array}{l}\text { This study } \\
(\mathrm{N}=348)\end{array}$ & $\begin{array}{l}\text { Chandley et al. }(1975) \\
\qquad(\mathrm{N}=1599)\end{array}$ & $\begin{array}{l}\text { Kjessler (1972) } \\
(\mathrm{N}=1263)\end{array}$ & \\
\hline $\begin{array}{l}\text { 47,XXY } \\
47, X X Y \text { mosaics }\end{array}$ & $\frac{2.87}{-}$ & $\begin{array}{c}10 \cdot 00 \\
-\end{array}$ & $\begin{array}{l}24 \cdot 54 \\
13.46\end{array}$ & $\begin{array}{c}(\mathrm{N}=34379 \text { males }) \\
0.96 \\
0.17\end{array}$ \\
\hline $\begin{array}{l}47, X Y Y \\
47, X Y Y \text { mosaics }\end{array}$ & $2 \cdot 87$ & $\begin{array}{l}1.88 \\
0.63\end{array}$ & $\overline{0.79}$ & $\begin{array}{l}0.81 \\
0.20\end{array}$ \\
\hline $45, X / 46, \operatorname{Xr}(Y)$ & - & 0.63 & - & - \\
\hline $45, X / 46, X Y$ & - & - & $7 \cdot 12$ & 0.03 \\
\hline$+\operatorname{mar}$ & $2 \cdot 87$ & $2 \cdot 50$ & $2 \cdot 38$ & $\begin{array}{c}(\mathrm{N}=54749 \text { newborn }) \\
0.22\end{array}$ \\
\hline$t(D q D q)$ & 5.75 & $1 \cdot 25$ & $5 \cdot 54$ & 0.79 \\
\hline Other translocations & 11.49 & $4 \cdot 37$ & 1.58 & 0.85 \\
\hline Inversions & 8.62 & - & - & 0.13 \\
\hline
\end{tabular}

may be a chance distribution it may also reflect social or psychological differences in our population which result in fewer patients with Klinefelter's syndrome coming to infertility clinics. Considering that these patients are inevitably infertile we should expect to find more than one in a series of this size unless there is some form of exclusion operating.

We find a similar incidence of 47,XYY males. The effect of this karyotype on fertility is not clear. Kjessler (1972) found only one XY/XYY mosaic in his survey although Chandley et al. (1975) found 3 XYYs and 1 XY/XYY mosaic. Some XYY individuals are fertile but Skakkebaek, Hultén, Jacobsen \& Mikkelsen (1973) reported that testicular biopsies from a series of XYY men, not selected for infertility, appeared to have impaired spermatogenesis. What we know of the social and behavioural characteristics of individuals with this sex chromosome complement might also lead to them being underrepresented at infertility clinics.

We encountered no sex chromosome mosaics in our study but this may be due to the limited number of cells examined from those bloods in which no chromosome abnormality was observed. Thus, in our study, and also that of Chandley et al. (1975), in which 10 cells were initially examined, only those patients with a significant frequency of abnormal cells would have been identified.

Individuals with an extra, unidentified marker chromosome appear in the newborn population at a frequency of 0.22 per thousand (Neilsen \& Sillesen, 1975); all three subfertility studies show a frequency at least 10 times as great, even though a proportion of those identified in the newborn surveys may subsequently enter mental deficiency institutions (see Newton, Cunningham, Jacobs, Price \& Fraser, 1972) and not appear at subfertility clinics.

Individuals with a 13/14 Robertsonian translocation from the three surveys combined are between 4 and 5 times more frequent than the newborn surveys would lead one to expect. Fraccaro et al. (1973) found 4 patients with a 13/14 Robertsonian translocation among 92 infertile males without hypogonadism or azoospermia. The $13 / 14$ form of the $\mathrm{D} / \mathrm{D}$ translocation is the most common arrangement, being found in all 9 such carriers in the newborn survey of Nielsen \& Sillesen (1975) and in 23 out of 24 cases ascertained by a variety of routes by Jacobs, Buckton, Cunningham \& Newton (1974). There does not appear to be any increased rate of infertility in the families of those individuals identified among the newborn (Nielsen \& Ramussen, 1976) but neither is there any evidence of familial infertility in the relatives of our two cases (Table 3). However, carriers of $D / D$ translocations have been shown to have a reduced reproductive fitness (Jacobs, Frackiewicz, Law, Hilditch \& Morton, 1975). 
Reciprocal translocations are strikingly increased in our study. It should be noted, however, that 2 of these cases were referred directly following a history of multiple abortions in their spouses. Although seminal specimens were not obtained from either of these men they were presumably not azoospermic as their spouses both achieved several pregnancies.

The carrier of an 8;9 translocation (L.C.) had a child with the same translocation and an additional chromosome 21. It has been suggested (Grell \& Valencia, 1964; Oikawa, Trent \& Lebovitz, 1977) that translocations may increase non-disjunction of chromosomes other than those involved in the translocation. However, as neither trisomy 21 nor reciprocal translocations are particularly unusual events this association may not infrequently occur by chance and only large studies on unselected cases of Down's syndrome or reciprocal translocation carriers can resolve the question.

The $\mathrm{X} / 21$ reciprocal translocation is of particular interest. We have been able to find only four previous reports of balanced reciprocal translocations between an $\mathrm{X}$ chromosome and an autosome in males (Buckton, Jacobs, Rae, Newton \& Sanger, 1971; Dutrillaux, Couturier, Rotman, Salat \& Lejeune, 1972; Stengel-Rutkowski et al., 1976; Turleau, Chavin-Colin, De Grouchy, Repesse \& Beauvais, 1977). In the three cases in which studies on spermatogenesis have been possible the patients, like our patient, have been azoospermic. It seems highly probable that X-autosome translocations, as has been discussed by Lifschytz \& Lindsley (1972), interfere with the normally separate activities of the sex chromosomes and the autosomes during spermatogenesis. It is tempting to speculate that cells with $47, \mathrm{XXY}, 47, \mathrm{XYY}$ or $\mathrm{X}$-autosome translocations may share an inability to form a satisfactory sex chromosome vesicle at zygotene. It is now clear from a number of studies that in general spermatocytes from XYY individuals, who are not azoospermic, have only one Y chromosome (Melnyk, Thompson, Rucci, Vanasek \& Hayes, 1969; Chandley, Fletcher \& Robinson, 1976; Faed, Robinson, MacIntosh \& Grieve, 1976).

Of special interest is our patient with a paracentric inversion of chromosome 7 . We are aware of only one other report of a paracentric inversion in man which also, remarkably, affects chromosome 7 (Shimba, Ohtaki, Tanabe \& Sofuni, 1976). A paracentric inversion might be expected to give rise at meiosis to some spermatocytes with a dicentric and a fragment, the size of the fragment and of the dicentric depending on the position of the inverted segment in the chromosome. The effect of this on spermatogenesis in man is not known. If viable, but unbalanced, spermatozoa are produced with a dicentric in this patient these would produce a zygote effectively trisomic for most of chromosome 7 .

We identified two individuals with pericentric inversions of the heterochromatic region of chromosome 9. This rearrangement, which is now widely recognized to be a frequent polymorphism in human populations, is found with a frequency of about 1 in 200 in the general Dundee population. Its possible role in fertility is uncertain.

Patient A.C. was found to have large, highly fiuorescent satellites on chromosome 22. Such fluorescent satellites have sometimes been considered to represent $\mathrm{Y}$ to autosome translocations (Chandley et al., 1975). We have no evidence on this point and prefer to regard our patient as being the carrier of a variant chromosome. In any event, this patient's azoospermia is more readily explained as a result of cystic fibrosis.

We have sought evidence of familial infertility by examining the sibship sizes of the patients and their first degree relatives. The patients' own sibships appear to be smaller than those of their parents but mean completed family sizes, for all women married once, also declined from 2.32 in 1920 to 2.00 in 1940 (Thompson \& Lewis, 1975). There is no evidence of infertility in either the maternal or paternal grandparents. Various explanations are possible but the number of patients in this study is too small to differentiate between them and certainly it would seem probable that a factor (e.g. sex) other than the chromosomal anomaly is also important in determining which individuals will reproduce without difficulty. 
We have been impressed by finding three translocation carriers and a paracentric inversion which can only be demonstrated by banded preparations of high quality. Although we have rejected a high proportion of our preparations as being unsatisfactory we still do not feel confident that in a survey such as this small rearrangements may not be overlooked. In addition some reciprocal exchanges may occur in which the banding pattern of the exchanged portions would be insufficiently different from trypsin/Giemsa banding to demonstrate them at all. The percentage of infertile individuals with rearrangements which we have found in this survey thus seems likely to be an underestimate of true incidences.

The role of chromosome abnormality in infertility appears to be 2 -fold. In most subfertile individuals with chromosome abnormality there is a reduction in sperm count when this has been examined. In others, however, there is an increased spontaneous abortion rate, implying fertilization by chromosomally unbalanced spermatozoa. Such individuals would therefore appear to have at least two hurdles to surmount before achieving a normal child and there are good grounds for undertaking antenatal screening in the spouses of men known to have chromosomal rearrangement.

We acknowledge the excellent, skilled assistance of Valerie Anderson, Sandra Reid, Doris McLean and Dorothy Mentiply.

\section{References}

Buckton, K.E., Jacobs, P.A., Rae, L.A., Newton, M.S. \& Sanger, R. (1971) An inherited X-autosome translocation in man. Ann. Hum. Genet. 35, 171-179.

Chandley, A.C., Edmond, P., Christie, S., Gowans, L., Fletcher, J., Frackiewicz, A. \& Newton, M. (1975) Cytogenetics and infertility in man. I. Karyotype and seminal analysis. Ann. Hum. Genet. 39, 231-254.

Chandley, A.C., Fletcher, J. \& Robinson, J.A. (1976) Normal meiosis in two $47, \mathrm{XYY}$ men. Hum. Genet. 33, 231-240.

Dutrillaux, B., Couturier, J., Rotman, J., Salat, J. \& Lejeune, J. (1972) Sterilité et translocation familiale t(1q-;Xq+). C. r. hebd. Séanc. Acad. Sci., Paris D 274, 3324-3327.

Faed, M., Robertson, J., MacIntosh, W.G. \& Grieve, J. (1976) Spermatogenesis in an infertile XYY man. Hum. Genet. 33, 341-347.

Fraccaro, M., Maraschio, P., Pasquali, F., Tiepolo, L., Zuffardi, O. \& Giarola, A. (1973) Male infertility and $13 / 14$ translocation. Lancet $\mathbf{i}, 488$.

Grell, R.F. \& Valencia, J.I. (1964) Distributive pairing and aneuploidy in man. Science, N.Y. 145, 66-67.

Jacobs, P.A., Buckton, K.E., Cunningham, C. \& Newton, M. (1974) An analysis of the breakpoints of structural rearrangements in man. $J$, med. Genet. 11 , 50-64.

Jacobs, P.A., Frackiewicz, A., Law, P., Hilditch, C.J. \& Morton, N.E. (1975) The effect of structural aberrations of the chromosomes on reproductive fitness in man. Clin. Genet, 8, 169-178.

Kjessler, B. (1972) Facteurs génétiques dans la subfertilité male humaine. In Fecondité et Sterilité du Male Acquisitions Récentes, pp. 202-225. Masson et Cie, Paris.

Koulischer, L. \& Schoysman, R. (1974) Chromosomes and Human Infertility. 1. Mitotic and meiotic chromosome studies in 202 consecutive male patients. Clin. Genet. 5, 116-126.

Lifschytz, E. \& Lindsley, D.L. (1972) The role of Xchromosome in inactivation during spermatogenesis. Proc. natn. Acad. Sci. U.S.A. 69, 182-186.
Melnyk, J., Thompson, H., Rucci, A., Vanasek, F. \& Hayes, S. (1969) Failure of transmission of the extra chromosome in subjects with $47, \mathrm{XYY}$ karyotype. Lancet ii, 797.

Newton, M.S., Cunningham, C., Jacobs, P.A., Price, W.H. \& Fraser, I.A. (1972) Chromosome survey of a hospital for the mentally subnormal. Part 2: Autosomal abnormalities. Clin. Genet. 3, 226-248.

Nielsen, J. \& Ramussen, K. (1976) Autosomal reciprocal translocations and $13 / 14$ translocations: a population study. Clin. Genet. 10, 161-177.

Nielsen, J. \& Sillesen, I. (1975) Incidence of chromosome aberrations among 11,148 newborn children. Hum. Genet. 30, 1-12.

Oikawa, K., Trent, M. \& Lebovitz, R. (1977) Familial balanced translocation $4 p+/ 17 q-$ as a suggested cause of primary trisomy -21 Down's syndrome. Arch. dis. Childh. 52, 890-893.

Seabright, M. (1971) A rapid banding technique for human chromosomes. Lancet ii, 971-972.

Shimba, H., Ohtaki, K., Tanabe, K. \& Sofuni, T. (1976) Paracentric inversion of a human chromosome 7 . Hum. Genet. 31, 107.

Skakkebaek, N.E, Hultén, M., Jacobsen, P. \& Mikkelsen, M. (1973) Quantification of human seminiferous epithelium. II. Histological studies in eight 47, XYY men. J. Reprod. Fert. 32, 391-401.

Stengel-Rutkowski, S., Zankl, H., Rodewald, A., Scharrer, S., Chaudhuri, J.P. \& Zang, K.D. (1976) Aspermia, associated with a presumably balanced $\mathrm{X}$ /autosome translocation. Karyotype $46, \mathrm{Y}, \mathrm{t}(\mathrm{X}$;5)(q28:q11). Hum. Genet. 31, 97-106.

Thompson, E.J. \& Lewis, C. (1975) Social Trends, No. 6, C.S.O., H.M.S.O. London.

Turleau, C., Chavin-Colin, F., De Grouchy, J., Repesse, G. \& Beauvais, P. (1977) Familial $t(X ; 2)(p 223 ;-$ q323) with partial trisomy $2 q$ and male and female balanced carriers. Hum. Genet. 37, 97-104. 